\title{
A IGREJA E O ESTADO: REFLEXÕES SOBRE A FORMAÇÃO DO PROFESSOR PRIMÁRIO NO PERÍODO DE 1946-1979
}

\author{
Michelle Castro Lima \\ Instituto Federal Goiano (IFGoiano - Campus Morrinhos), Morrinhos, \\ Goiás, Brasil \\ ANTÔNIO GOMES FERREIRA \\ Universidade de Coimbra (UC.PT), Coimbra, Portugal
}

\begin{abstract}
Resumo: O estudo sobre a formação do professor primário é de fundamental importância para o entendimento acerca da constituição da sociedade e os diferentes papéis assumidos pela Igreja Católica que, historicamente, usufruiu do poder da educação para manutenção de controle social. Este estudo buscou analisar a relação da Igreja Católica com a formação de professores no Triângulo Mineiro MG, no período de 1946 a 1979. Para tal, investigamos, em trabalhos de pósgraduação Stricto Sensu que discutem a formação do professor primário no Triângulo Mineiro, o estado da arte desse tema. Encontramos 20 trabalhos que o abordam, tendo como sujeitos 43 professores primários, dos quais 21 estudaram em escolas confessionais e 22 professores que, embora tivessem estudado em escolas laicas, difundiam em suas falas os preceitos difundidos pela Igreja Católica no período de 1946 a 1979. Utilizamos como metodologia a Análise de Conteúdo segundo Bardin (2016). A partir das análises, identificamos que a Igreja foi um instrumento em parceria com o Estado para a manutenção da ordem social vigente no período de 1946 a 1979. Desta forma, os preceitos difundidos pela Igreja Católica foram divulgados nas escolas católicas e nas escolas laicas.
\end{abstract}

Palavras-chave: Igreja. Formação de Professores. Mulher. Estado.

INTRODUÇÃO

Este artigo é um recorte de uma pesquisa mais ampla que visou mapear as teses e dissertações sobre formação de alfabetizadoras no Triângulo Mineiro no período de 1946 a 1979. A delimitação do início de pesquisa ocorreu devido à promulgação do Decreto-Lei no 8.530, de 02 de janeiro de 1946, que regulamentou o Ensino Normal no Brasil. Esse decreto é importante quando abordamos a formação de professores, pois ofereceu as novas diretrizes nacionais para a formação do professor do ensino primário no curso Normal estabelecendo três tipos de Ensino Normal: curso normal regional, a escola normal e o instituto de educação. De acordo com a Lei Orgânica do Ensino Normal, 
[...] os poderes públicos federais e estaduais devem desenvolver a rede de estabelecimento de ensino normal, mediante conveniente planejamento, a fim de que no devido tempo e onde se torne necessário, haja em número e qualidade os docentes reclamados pela expansão dos serviços de ensino primário (BRASIL, 1946, art. 39).

A pesquisa se encerra em 1979, quando houve mudança no processo de alfabetização e de formação do alfabetizador devido à publicação em português do livro "Psicogênese da Língua Escrita", de Ferreiro e Teberosky (1991), que, apresentando novos conceitos sobre o processo de alfabetização, influenciou a prática e a formação das professoras alfabetizadoras.

Em 1971, ocorreu a promulgação da Lei 5692/71, que extinguiu a nomenclatura Grupos Escolares e diluiu as Escolas Normais, pois tornou o segundo grau profissionalizante. Assim, surgiu o Magistério com duração de três anos e carga horária de 2.200 horas, como uma habilitação para a docência no $1^{\circ} \mathrm{grau}$, mais especificamente para a docência até a $4^{a}$ série. "A formação de professores para o antigo ensino primário foi, pois, reduzida a uma habilitação dispersa em meio a tantas outras, configurando um quadro de precariedade bastante preocupante [...]." (SAVIANI, 2009. p. 147). Dessa forma, o curso Normal foi reduzido a mais uma das habilitações do segundo grau e perdeu espaço e as especificidades próprias das estruturas que ofereciam aquela modalidade.

A formação dos alfabetizadores no período de 1946 a 1979 se deu basicamente em Escolas Normais. Contudo, encontramos nesta pesquisa algumas alfabetizadoras leigas e outras que cursaram o Magistério. Devemos relembrar que durante o período pesquisado houve movimentos sociais, leis e decretos importantes para o desenvolvimento da educação no Brasil. Dentre eles, é importante destacar que em 1946 ocorreu a reforma do ensino primário e do Ensino Normal e em 1964 se concretizou o golpe militar, que acarretou diversas mudanças na legislação educacional, como a de nomenclatura do ensino primário.

Diante desse contexto, foram selecionadas e analisadas 05 teses e 15 dissertações que abordam a história da alfabetização no Triângulo Mineiro e Alto Paranaíba no período de 1946 a 1979. Para tal, realizamos uma pesquisa nos bancos de teses e dissertações, Banco de teses Coordenação de Aperfeiçoamento de Pessoal de Nível Superior (CAPES) e Biblioteca Digital Brasileira de Teses e Dissertações/ Instituto Brasileiro de Informação em Ciência e Tecnologia (IBICT), a fim de identificar os trabalhos de pós-graduação que abordassem a temática história da formação das alfabetizadoras naquelas duas regiões de Minas Gerais.

A seleção das dissertações e teses utilizadas nesta pesquisa ocorreu a partir da análise inicial dos resumos dos trabalhos encontrados que faziam parte do tema e do recorte temporal estabelecido. Após essa primeira seleção, analisamos os textos completos. Utilizamos como aporte teórico a Nova História Cultural, a qual abre novas possibilidades de pesquisa. Essa opção se deve ao fato de que "A base filosófica da Nova História é a ideia de que a realidade é social ou culturalmente constituída" (BURKE, 1992, p. 11), o que corrobora nossa convicção. Dessa forma, utilizamos como fonte e objeto as 
teses e dissertações selecionadas. Inicialmente, estabelecemos como filtro para a pesquisa nos bancos de teses e dissertações os seguintes termos: formação de professoras primárias, formação de professores primários, formação de alfabetizadoras, formação de alfabetizadores, história de alfabetizadores de Minas Gerais, história da alfabetização de Minas Gerais, alfabetizadoras em Minas Gerais, práticas de alfabetizadoras em Minas Gerais e Alfabetização e formação em Minas Gerais.

Como suporte metodológico para a pesquisa utilizamos a análise de conteúdo que

\begin{abstract}
é uma técnica de análise de dados, colhidos em várias fontes, mas expressos, preferencialmente, em textos ou em imagens. A natureza destes documentos pode ser muito variada, tal como material de arquivo, textos literários, relatórios, notícias, comentários avaliativos de determinada situação, diários e autobiografias, artigos selecionados através do método de revisão da literatura, transcrições de entrevistas, textos solicitados sobre um determinado tema, notas de campo, etc. etc. O mesmo se poderá dizer quanto à natureza das imagens: fotografias, filmes, ilustrações de livros, etc. (COSTA; AMADO, 2018, p. 9).
\end{abstract}

Segundo Bardin (2016), a análise de conteúdo está organizada em três fases: préanálise, exploração do material e tratamento dos resultados, inferência e interpretação. Desta forma, na pré-análise selecionamos 20 trabalhos de pós-graduação stricto senso que abordam a história da alfabetização no Triângulo Mineiro. Transformamos o conteúdo das teses e dissertações em unidades de análise, realizamos a classificação das unidades de contexto, de tal modo que serviram de referência e fixação de limites contextuais para a interpretação das unidades. Na construção deste trabalho, utilizamos três unidades: formação de alfabetizadoras, Igreja e feminização. Contudo, daremos um destaque para a unidade "Igreja".

Nos trabalhos selecionados, identificamos que as pesquisas sobre as Escolas Normais, em sua maioria, se referem às escolas normais confessionais. Isso é intrigante, já que no recorte cronológico da pesquisa também existiam escolas normais não confessionais, como se vê no caso de quatro alfabetizadoras entrevistadas no trabalho "Ser professora na República: Modos de Pensar, sentir e agir (1930-1950)", de autoria de Martins (2010), que cursaram o Ensino Normal em um colégio não confessional (Escola Normal Prof. José Inácio de Souza). Além dessas professoras, encontramos nos outros trabalhos selecionados mais sete alfabetizadores que estudaram em escolas laicas, quatro professoras leigas e outros cinco professores cujo local de formação não foi possível identificar, mas, deles, três fizeram o curso Normal e dois, o Magistério.

Depois da leitura dos trabalhos observamos traços ligados à moral religiosa em todos os trabalhos selecionados. Desta forma, independente da Escola Normal ser confessional ou laica, todas as escolas divulgavam a moral católica, que deveria ser a base da formação das professoras alfabetizadoras. 


\section{A IGREJA CATÓLICA E A EDUCAÇÃO}

No século XIX, os princípios disseminados pela Igreja Católica apresentavam uma concepção de sociedade, poder e relações familiares que era apropriada à subsistência da elite brasileira. Apesar dos ideais liberalistas propagados pela elite reforçarem o caráter individualista e o civismo como força propulsora da Nação, a educação católica apregoava esses interesses na medida em que ensinava aos seus fiéis e alunos a ordem, a obediência e o respeito às normas instituídas. Dessa forma, a expansão da Igreja Católica no contexto educacional brasileiro se deu graças ao acordo da Igreja com as elites locais. Essa parceria foi profícua no estado de Minas Gerais, que, por um longo período, delegou a educação dos filhos da elite mineira às congregações estrangeiras católicas.

A escola sempre desempenhou um importante papel na constituição da sociedade ao ser uma disseminadora de valores e costumes. O episcopado, em sua política educacional, buscou diferentes instituições religiosas para atuarem no Brasil. Em diferentes momentos históricos, os bispos buscavam colaboradores para levar a educação religiosa ao povo.

As congregações religiosas, masculinas e femininas, virão encarregar-se desse serviço que para elas era também obra da Igreja. É impressionante, comparando-se com outras tarefas, o número de institutos religiosos que se fixam ou são criados no Brasil para atender ao mercado das escolas e colégios. Será por meio deles que o catolicismo prestará serviços preciosos à classe média e alta [...] (LUSTOSA, 1977, p.54).

Confirmando o destaque dessa missão que a Igreja se incumbia de exercer junto ao povo brasileiro, em 1930 cerca de $80 \%$ dos alunos secundaristas estudavam em escolas particulares e a maior parte delas (3/4) pertencia à Igreja Católica, conforme nos informa Moura (2000).

Ao longo do século XIX, a educação pública foi normatizada legalmente, contudo, na prática, ela continuava acontecendo em espaços privados. Durante a República houve certo progresso em direção ao sistema de educação pública. Gradativamente a Educação delimitou seu espaço no governo federal e começou a ser reconhecida como uma questão nacional quando, após a revolução de 1930, foi criado o Ministério da Educação e Saúde Pública.

Com a proclamação da República e consequente introdução do ensino laico, abriu-se espaço na educação brasileira para outros credos religiosos, além do catolicismo, que deixou de ser a religião oficial do país. Contudo,

Para a Igreja e para os católicos conservadores dos tempos republicanos, a ausência de educação religiosa nas escolas seria especialmente danosa às mulheres, que imbuídas de falsos preceitos e sem a benéfica influência da religião, contaminariam e perturbariam o lar católico, que deveria ser modelado pelos princípios cristãos (ALMEIDA, 2004, p.69). 
Nesse contexto, em decorrência de um possível "perigo" para as mulheres e a constituição do núcleo familiar, e levando-se em consideração a aproximação de outros credos, a Igreja temia um possível afastamento do Estado. Assim, ela precisava criar estratégias para se fortalecer novamente no seio da sociedade brasileira, aproveitando-se do fato de a maioria da população se declarar católica. Uma destas ferramentas foi o investimento no ensino privado confessional e, posteriormente, já na década de 60, em outras áreas da sociedade.

Em âmbito nacional, é relevante destacarmos que a Igreja Católica Brasileira sofreu uma crise após a Segunda Guerra mundial. Segundo Mainwaring (1989), a crise foi resultado

De uma rápida transformação da sociedade sem que houvesse uma mudança correspondente por parte da Igreja. As manifestações da crise incluíram uma resistência à secularização, o alarmante crescimento do protestantismo e do espiritismo, menor comparecimento à missa, uma crise de vocações, o crescimento da esquerda, e uma perda de influência entre as classes dominantes e entre a classe operária urbana. Os lideres mais proeminentes da Igreja sentiram que essas mudanças ameaçavam a instituição (MAINWARING, 1989, p. 33).

Apesar dessas mudanças serem explicadas pelas mudanças na política internacional, ela não justificou o caminho trilhado pela Igreja no Brasil. A Igreja continuou a investir na educação como forma de disseminar sua missão e intervir na política Brasileira.

A educação ministrada pela Igreja Católica sempre se aproximou da educação da elite, pois os colégios eram pagos e muitos funcionavam como internatos. Para aquelas alunas que iam estudar no sistema de internato, era necessário realizar o pagamento da pensão e do colégio. Também era solicitado um enxoval constituído de diversos itens, como, por exemplo, lençóis. Assim, havia um custo que inviabilizava a popularização desse modelo de ensino.

Nas escolas confessionais era marcante a presença das capelas em sua estrutura física. Além disso, havia a obrigatoriedade de frequência aos cultos para as alunas. $\mathrm{Na}$ figura a seguir, apresentamos um exemplo de uma Capela situada no interior do Colégio Sagrado Coração. 
Figura 1 - Interior Capela do Colégio Sagrado Coração na década de 30

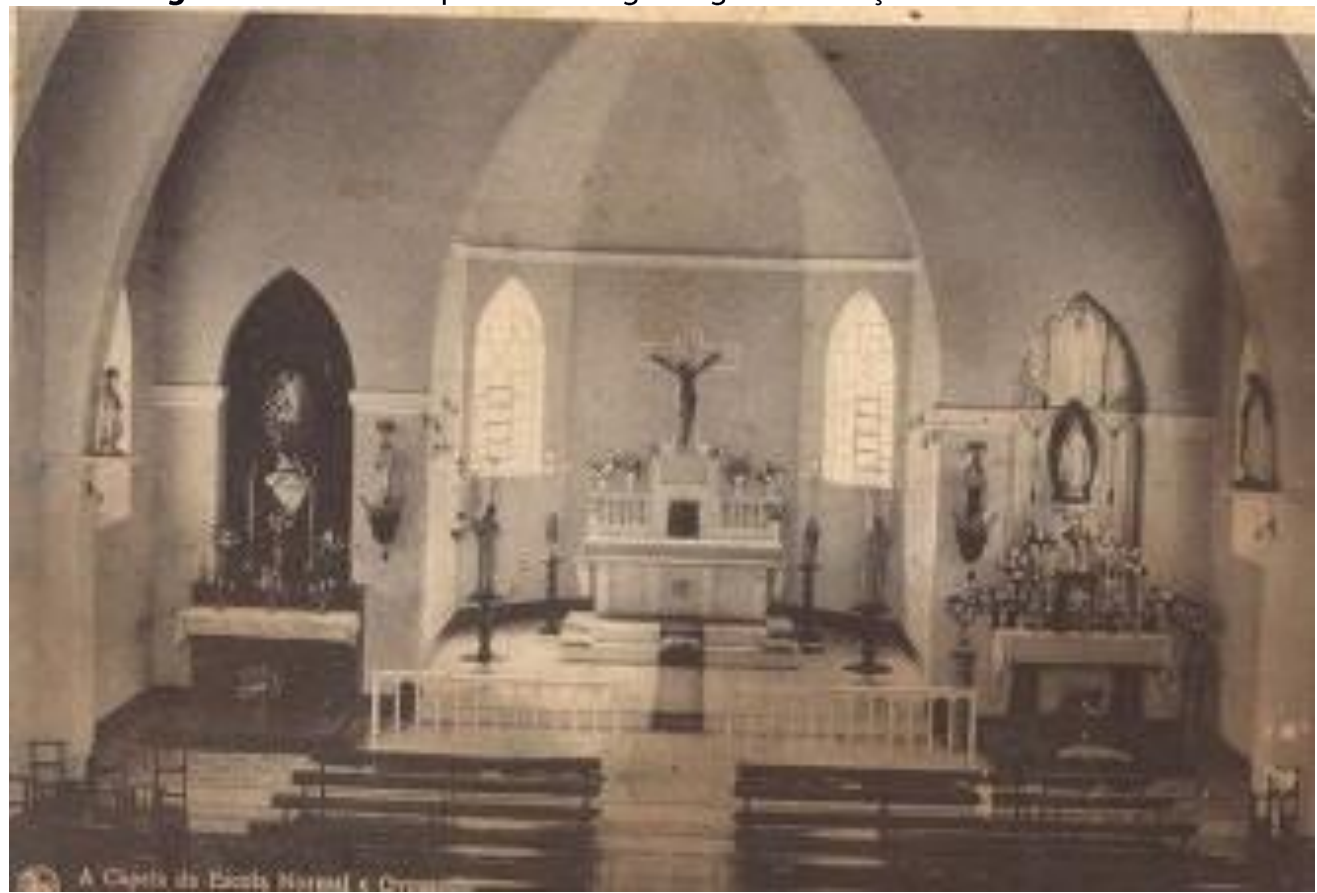

Fonte: Acervo da Instituição (SILVA, 2006, p. 80).

Para as alunas que apenas estudavam e não residiam nas escolas confessionais, havia uma orientação de que deveriam participar dos cultos de domingo. Assim, a construção dos colégios católicos estava engajada nos interesses de evangelização e manutenção da ordem. A Igreja Católica propagou a importância da formação moral e os riscos sociais das mudanças que estavam acontecendo no país durante o período pesquisado. Para a instituição, a escola deveria funcionar como responsável pela manutenção dos papéis culturalmente estabelecidos.

A Figura 2 mostra a presença uniforme de mulheres no Colégio e também destaca, no centro, a importância de uma imagem católica como um símbolo pertencente à cultura religiosa que deveria ser divulgada. 
Figura 2 - Normalistas no pátio do Colégio Normal Nossa Senhora do Patrocínio em 1946.

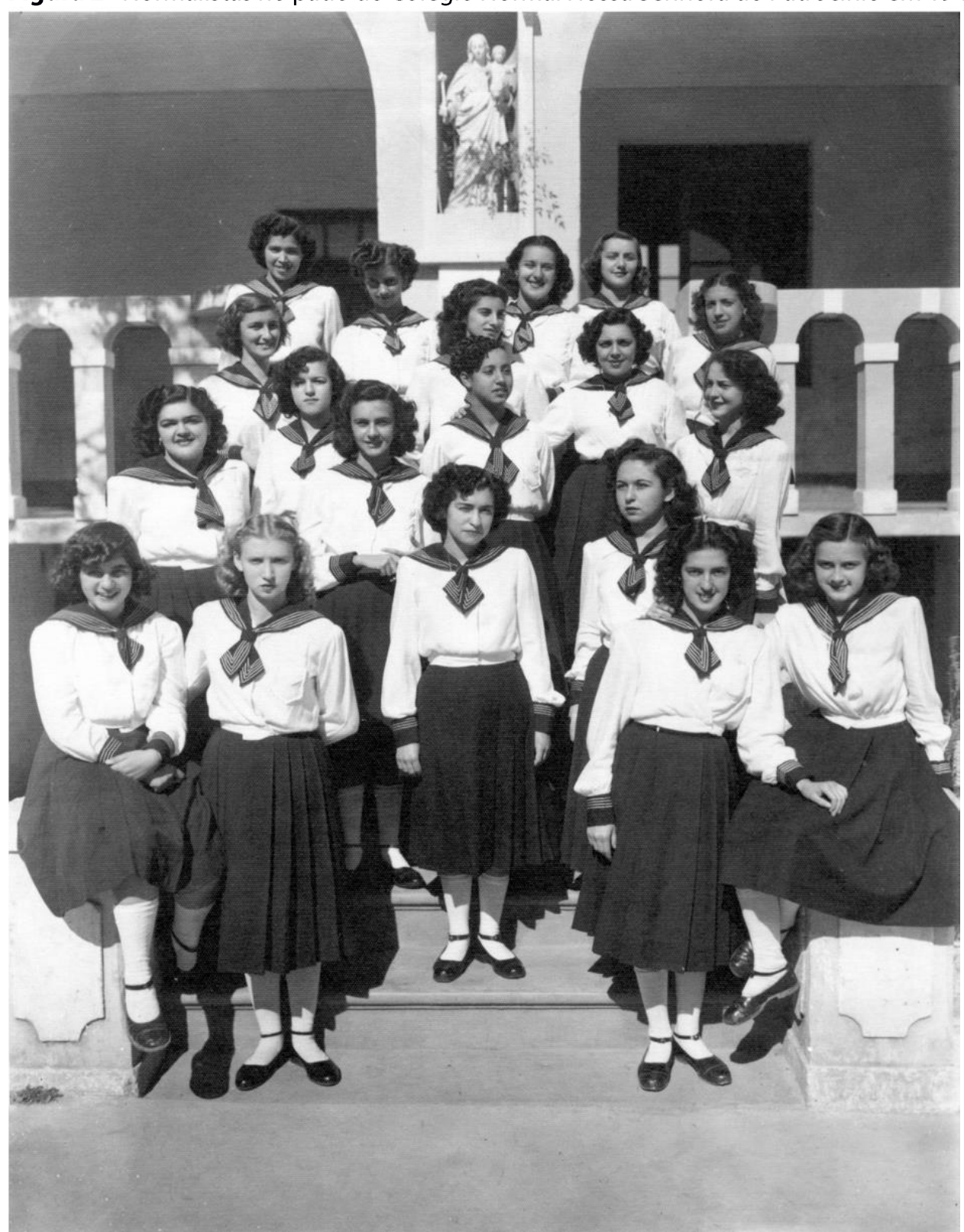

Fonte: Ferreira, 2006, p. 216.

No interior das salas de aula também eram marcantes os valores e símbolos cristãos. A sala de aula, a capela e o grupo de alunas apresentam de maneira evidente os 
princípios e a proximidade entre a igreja e a escola em um contexto político importante para a história brasileira.

Durante o Estado Novo, a Igreja esteve muito próxima do Governo de Getúlio Vargas, promovendo um fortalecimento da Instituição católica na sociedade. Nesse período, ficou estabelecido que seus fiéis deveriam colocar seus filhos para estudar nas Escolas Confessionais Católicas, que ofereciam às famílias tradicionais e abastadas uma formação diferenciada de acordo com o sexo: para os meninos, a preparação para o ensino superior, bem como para a vida política e para os empreendimentos econômicos; para as meninas, a manutenção do lar, em que se esperava da mulher quesitos relacionados à conservação do casamento e à educação dos filhos a partir dos preceitos morais da Igreja Católica. O ensino se mostrava diferenciado por sexo com escolas próprias para os meninos e para as meninas. Segundo Ferreira (2006), os colégios confessionais disseminavam uma "[...] formação que reproduzia a partilha cultural entre os universos masculino e feminino, uma vez que preparava os meninos para atuarem, posteriormente, no espaço público, e as meninas, para futuro desempenho no espaço privado." (FERREIRA, 2006, p. 159).

No contexto social de separação entre a Igreja e Estado, observamos um duplo movimento assumido pela nossa elite: por um lado, ela se posicionava de maneira contrária ao apoio financeiro do Estado à Igreja e buscava a concretização da separação de ambos, por outro, fortalecia e financiava a Igreja Católica ao matricular seus filhos e filhas nos colégios religiosos.

\begin{abstract}
[...] se a Igreja ia buscar apoio financeiro e político junto à oligarquia, a oligarquia Ihe amparou decididamente porque sabia que o seu projeto educacional, e mesmo o conjunto da política ultramontana ${ }^{1}$, Ihe era duplamente favorável: primeiro, porque Ihe reservava a função de dirigente da sociedade, cabendo-lhe, assim, a produção das ideias norteadoras do conjunto social. Segundo, porque o discurso antimoderno do catolicismo ultramontano tanto Ihe garantia a execução de um projeto educacional não A partir do apoio recebido junto à oligarquia, diferentes congregações estrangeiras implantaram pelo país seus colégios de ensino primário, secundário e até universidades. Esses colégios funcionavam em três modalidades: externato, internato e semi-internato. Observamos também que, até o início da década de 1970, o governo não fazia grande investimento nas escolas públicas secundárias, fortalecendo ainda mais a demanda de ensino nas escolas confessionais. Assim, a Igreja investiu na formação educacional da sociedade brasileira difundindo seus princípios e mantendo-se como religião da maior parte da população brasileira. Comprometedor e uma doutrinação de passividade, quanto, de fato, não obstava os necessários avanços e modernizações no âmbito das forças produtivas. (MANOEL, 1996, p. 102).
\end{abstract}

A Igreja Católica iria assumir uma posição diferente na política Brasileira, pois como qualquer outra instituição ela é "influenciada pelas mudanças na sociedade em geral". (MAINWARING, 1989, p. 25). Dessa forma, as ideologias políticas influenciaram a concepção de fé da Igreja (MAINWARING, 1989), o que levou a uma mudança de fé da Igreja Católica e a um novo modo de entender a realidade. 


\section{O PAPEL DA IGREJA CATÓLICA NA FORMAÇÃO DAS PROFESSORAS}

A partir da análise dos 20 trabalhos selecionados (cinco teses de doutorado e 15 dissertações de mestrado) nos bancos de teses e dissertações (Banco de teses Coordenação de Aperfeiçoamento de Pessoal de Nível Superior - CAPES e Biblioteca Digital Brasileira de Teses e Dissertações/Instituto Brasileiro de Informação em Ciência e Tecnologia - IBICT) encontramos oito trabalhos que têm como foco a Escola Normal, dois dos quais abordam a Escola Normal não confessional e um, as Escolas Normais de Ituiutaba (confessionais e laicas). Conforme podemos observar no Quadro 1, verificamos que oito instituições são confessionais, sendo uma de orientação espírita e todas as demais ligadas a ordens religiosas católicas.

Quadro 1 - As Escolas Normais e as instituições mantenedoras.

\begin{tabular}{|l|l|l|}
\hline & Título do Trabalho & Instituição mantenedora \\
\hline 1 & $\begin{array}{l}\text { Colégio Normal Nossa Senhora do } \\
\text { Patrocínio }\end{array}$ & Irmãs do Sagrado Coração de Maria \\
\hline 2 & $\begin{array}{l}\text { Escola Normal Dr. Benedito } \\
\text { Valadares }\end{array}$ & Particular e laica \\
\hline 3 & Escola Normal Oficial de Uberaba & Pública - não confessional \\
\hline 4 & Colégio Nossa Senhora doAmparo & $\begin{array}{l}\text { Irmãs Franciscanas de Nossa Senhora } \\
\text { do Amparo }\end{array}$ \\
\hline 5 & Escola Normal de Patos de Minas & Pública - não confessional \\
\hline 6 & Colégio Imaculada Conceição & $\begin{array}{l}\text { Congregação das Filhas de Nossa } \\
\text { Senhora do Monte Calvário }\end{array}$ \\
\hline 7 & $\begin{array}{l}\text { Curso Normal do Colégio Sagrado } \\
\text { Coração de Jesus }\end{array}$ & $\begin{array}{l}\text { Congregação do Sagrado Coração de } \\
\text { Maria. }\end{array}$ \\
\hline 8 & Colégio N. Sra. das Dores - Uberaba & $\begin{array}{l}\text { Irmãs da Congregação Dominicana de } \\
\text { Monteils }\end{array}$ \\
\hline 09 & Escola Normal Santa Teresa & Irmãs Scalabrinianas \\
\hline 10 & $\begin{array}{l}\text { Colégio Normal do "Educandário } \\
\text { Ituiutabano" }\end{array}$ & $\begin{array}{l}\text { União da Mocidade Espírita de } \\
\text { Ituiutaba }\end{array}$ \\
\hline 11 & Colégio Normal do Colégio São José. & Padres Estigmatinos \\
\hline 12 & Colégio Normal Municipal. & Público e laico \\
\hline
\end{tabular}

Fonte: Elaborado pela autora.

No período existiam outras escolas não confessionais que atuavam na formação do professor primário, porém não encontramos muitos trabalhos sobre elas. Identificamos que as escolas confessionais de curso Normal eram as mais renomadas na região, atendendo alunas de todo o Triângulo Mineiro e de outros estados. As famílias abastadas desejavam que suas filhas se formassem nas escolas Normais religiosas. 
Segundo Lopes (2003), durante muitos anos a mulher não teve acesso à educação e, quando passou a tê-lo, foi principalmente em instituições religiosas. Das professoras alfabetizadoras identificadas nos trabalhos, a quantidade de professoras formadas em escolas confessionais é maior do que a de formadas em escolas laicas.

Destacamos também que cinco professores são identificados como leigos e dois não declararam, conforme gráfico a seguir:

Gráfico 1 - Local de formação dos professores alfabetizadores

\title{
Local de formação dos professores alfabetizadores
}

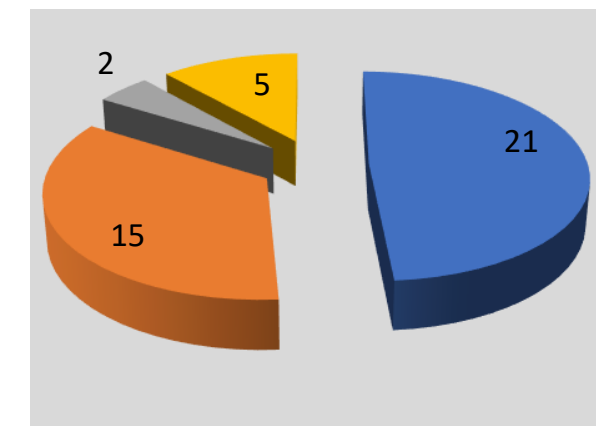

\author{
- Escolas \\ Confessionais \\ Escolas Laicas \\ Não declarada \\ Professor leigo
}

Fonte: Elaborado pela autora.

Foram selecionados 20 trabalhos tendo como sujeitos 43 professores primários, conforme o Gráfico 1 aponta. Assim, observamos novamente a forte atuação da igreja na formação dos professores com a presença de 21 escolas confessionais num conjunto de 43. Os outros 22 professores, embora tenham estudado em escolas laicas, disseminavam em suas falas os princípios da Igreja Católica.

\subsubsection{A presença da igreja retratada nos trabalhos}

Os documentos das instituições são fontes muito úteis para a compreensão das posições da Igreja no que diz respeito à educação da mulher e ao papel que lhe competia na sociedade. Nos 20 trabalhos selecionados, identificamos como a formação das professoras alfabetizadoras foi conduzida pelas organizações de caráter confessional a partir de valores e comportamentos. Embora as práticas educacionais católicas fossem norteadas pelos documentos oficiais da Igreja, a noção de apropriação apresentada por Chartier (1990) sugere que a anuência e apropriação das mensagens e práticas muitas 
vezes aconteciam de forma diversificada, pois "a aceitação das mensagens e dos modelos opera-se sempre através de ordenamentos, de desvios, de reempregos singulares que são objeto fundamental da história cultural." (CHARTIER, 1990, p.137).

Nos trabalhos analisados identificamos o retrato da relação da mulher na sociedade machista e patriarcal. A igreja era um dos lugares mais importantes de sociabilidade da mulher e essa mulher ganhou o espaço do magistério quando, após diversas transformações sociais no fim do século XIX, passou a ser vista como responsável pela educação dos homens, motivo pelo qual deveria ser educada e formada "[...] para bem educar o homem." (MELO, 2002, p. 68). Observamos também o papel da Igreja na formação da professora nos ritos e organização do colégio, ao estabelecer os espaços de forma que as religiosas conseguissem vigiar a movimentação das alunas.

A questão disciplinar no colégio era muito rígida, não sendo permitido às internas conversar durante as aulas e nos corredores. As alunas andavam em filas que deveriam ser organizadas. O Colégio Nossa Senhora das Dores de Uberaba trabalhou os valores essenciais para a sociedade católica, como a moral e o papel da mulher na sociedade.

Os valores morais eram altamente disseminados através das práticas que compunham o cotidiano das alunas: a postura; a maneira de andar, sentar, conversar; o uniforme (saias compridas, blusas de mangas longas). Nas aulas de Religião e de Polidez, a moral e os bons costumes eram amplamente ensinados pelas mestras, dando continuidade aos ensinamentos da família, visto que a maioria das alunas que estudou no Colégio, principalmente as internas, originava-se de famílias católicas (MELO, 2002, p.99).

Essas escolas impunham uma rotina rígida. Todos os dias as alunas se levantavam às cinco horas da manhã e, após se vestirem e realizarem a higiene pessoal, eram encaminhadas em fila para assistirem a primeira missa na capela. Segundo relato de alunas que estudaram no Colégio Nossa Senhora das Dores em Uberaba, havia um discurso que relacionava a imagem da Virgem Maria à imagem da mulher. Assim, elas deveriam se espelhar na Virgem Maria para não decepcionar a sociedade.

Pureza e castidade eram valores muito importantes na época. O Colégio tinha seus rigores, sua disciplina [...]. Tínhamos que ter postura, não se podia sentar de qualquer jeito, é lógico que sempre tinha aquelas mais levadas, as indisciplinadas, como hoje. Não é porque havia essa rigidez que não tinha indisciplina, existia sim, mas o Colégio procurava conter os casos que apareciam, nós éramos muito "contidas" (MARIA DÉLIA, apud MELO, 2002, p.77).

A escola, segundo a autora, preservava os valores morais católicos e divulgavaos para as alunas em rituais.

Sendo assim, no que diz respeito ao rigor disciplinar, que se traduz em uma marca característica de escolas com perfil similar, todas as ex-alunas concordaram em que as normas de convivência eram rígidas. A leitura do rigor identificado, contudo, vem associada a situações peculiares. A ênfase recaiu sempre na questão da fiscalização do uniforme à entrada do Colégio e na figura da Irmã responsável por este 
procedimento, que era sempre a Madre Superiora (MELO, 2002. p. 169-170).

A professora era respeitada dentro e fora da sala de aula. No colégio havia algumas restrições de acesso a certos espaços, por exemplo, aos aposentos das freiras, e isso era muito respeitado pelas alunas. Neves (2005) também retrata a rotina das alunas que tinham os momentos de oração, de atividades recreativas e participação em comemorações cívicas ou religiosas.

A lgreja teve um papel importante na manutenção da ordem social, da separação das classes sociais e de gênero ao se propor educar as mulheres para o magistério primário a partir das atividades domésticas de uma mulher casada. A ideia da Congregação dos Sagrados Corações de Jesus e de Maria era conduzir a internalização do Catolicismo na vida de seus fiéis.

Além disso, a obra educacional empreendida pelos religiosos e religiosas da Congregação dos Sagrados Corações de Jesus e de Maria inscrevia-se em um projeto maior do Bispado de Uberaba, de reforma do clero e dos costumes, com a finalidade última de internalização do Catolicismo na vida cotidiana dos fiéis nas Zonas do Triângulo e do Alto Paranaíba em Minas Gerais (FERREIRA, 2006, p.184).

O Colégio Normal Nossa Senhora do Patrocínio seguia os ritos dos colégios católicos com rigidez e disciplina. Ele divulgava os valores morais do catolicismo a partir de sua grade curricular com as disciplinas de Catecismo e História Sagrada, além de Religião.

Os Colégios confessionais do curso Normal valorizavam os princípios religiosos enaltecendo a função e importância da família, bem como a formação moral e religiosa de suas alunas. Segundo uma ex-aluna:

Eu fui estudar no colégio porque na época existiam duas escolas na cidade, o colégio dos padres e o colégio das freiras. No das freiras só estudavam mulheres, então tive que ir pra lá. A família da gente achava importante estudar em um colégio de freiras. A formação moral e religiosa para os pais daquela época era muito importante. $O$ sonho dos pais é que suas filhas estudassem num colégio que se preocupava em dar uma educação que iria formar o caráter e ensinaria religião católica (ENTREVISTA No 5, 2010 apud ROZETTI, 2011, p.106).

Nessa pesquisa fica evidenciada a função da Igreja Católica no sentido de manutenção da ordem social vigente propagando os ideais católicos. Com relação aos conteúdos curriculares, o Colégio seguia as normativas da Lei $n^{\circ} 8.530$ de 1946 . Ferreira (2006) relata em sua pesquisa como a lgreja teve um papel importante na manutenção da ordem social.

Em todos os trabalhos identificamos que nos colégios normais particulares havia uma diferenciação no trato das alunas bolsistas em relação às outras alunas. As alunas bolsistas eram obrigadas a se dedicarem às atividades de limpeza da instituição, bem como trabalhavam no refeitório e na lavanderia, enquanto as outras alunas poderiam frequentar as aulas de francês e piano, que na maioria dos colégios eram cursos pagos 
separadamente. Além disso, podemos observar que a questão da disciplina também aparece em todos os trabalhos como um ritual importante para formação da mulher mãe/esposa/professora.

$\mathrm{Na}$ análise dos trabalhos fica evidente um modelo de mulher criado desde meados do século XIX.

[...] inspirado nos arquétipos do cristianismo, espelhava a cultura vigente instituindo formas de comportamento em que se exaltavam virtudes femininas como castidade e abnegação, forjando uma representação simbólica de mulher por meio de uma ideologia imposta pela religião e pela sociedade, na qual o perigo era principalmente representado pela sexualidade. Essa ideologia vai desqualificar a mulher do ponto de vista profissional, político e intelectual (ALMEIDA, 2004, p. 68).

Este modelo pode ser representado de modo esquemático na figura a seguir, com base nos relatos das professoras presentes nos trabalhos.

Figura 3 - Formação de professoras alfabetizadoras: Igreja Católica e o Estado/Sociedade

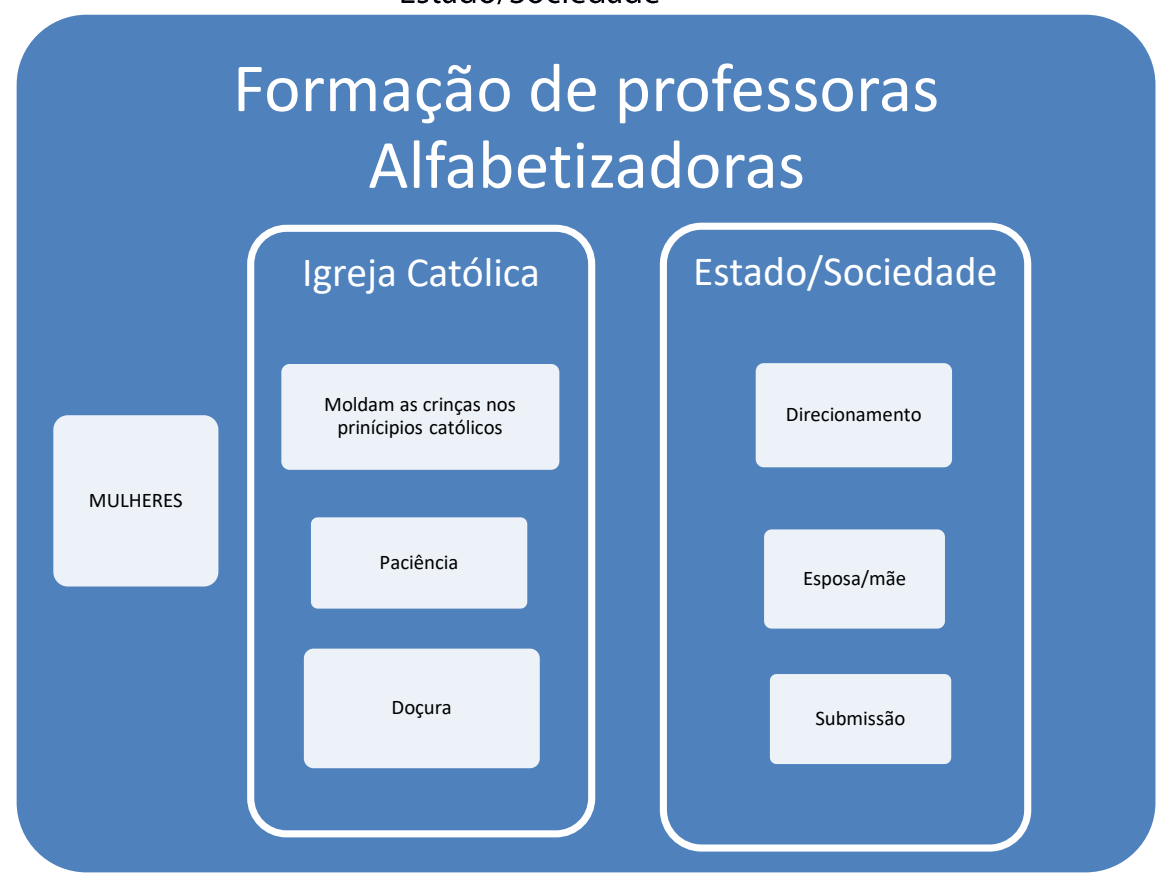

Fonte: Elaborado pela autora.

As mulheres, segundo a Igreja Católica e o Estado/Sociedade, estavam mais preparadas para a tarefa de educar as crianças, pois, segundo essas instituições, tinham os atributos necessários à manutenção e disseminação de valores e princípios apregoados no âmbito cristão e social. 


\section{CONSIDERAÇÕES FINAIS}

A Igreja auxiliou a divulgar e reforçar o imaginário social que redefine o papel feminino, enaltecendo a importância do amor e do cuidado com os filhos. A mulher, que ao mesmo tempo se dedica às atividades no interior do espaço doméstico, devia também ser educada para garantir seu papel na sociedade de educar seus filhos. A partir dessa ideia, a concepção de mulher/mãe/professora é amplificada como se esta tríade fosse elemento singular da mulher, já que para educar as crianças é necessário ter amor, paciência e dom, inseridos nos princípios morais e éticos defendidos pela sociedade católica. Nesse arcabouço de valores apregoados e difundidos pela igreja, a pessoa mais indicada para desempenhar esse papel é a mulher, que já ocupava papel semelhante no interior da família.

A partir da pesquisa, observamos que, mesmo nas escolas declaradas laicas, encontramos preceitos católicos divulgados na formação da mulher professora alfabetizadora. Com a imbricação entre a igreja e a escola, se tornou impossível separar a influência da Igreja Católica da formação da mulher para docência do ensino primário, pois esta ideia fazia parte das concepções de manutenção da sociedade católica.

Assim, as questões da disciplina e da formação para ser professora, como o melhor espaço para uma mulher honrada, são unânimes no discurso da Igreja e das Escolas Normais. Nas falas das alfabetizadoras identificamos a forte associação entre as ideias de mulher, mãe e professora. Essa relação, por muito tempo difundida pela Igreja Católica, foi apropriada pela sociedade, que reconheceu no magistério primário o local específico para a mulher.

A formação para atuar no ensino primário se pautou nas questões religiosas no sentido de manutenção da ordem e da moral católica. Assim, escolas de formação de professoras, em consonância com os princípios cristãos difundidos socialmente, empregavam um discurso de destaque para o aprimoramento dos valores morais e de que suas alunas, após terem frequentado suas atividades, aprenderiam comportamentos sociais, regras de convivência, musicalização, idiomas e questões relacionadas com o cuidado do lar.

Os Cursos Normais, em sua matriz curricular, apresentavam muitas disciplinas humanísticas de cunho geral e apenas no último ano eram apresentadas disciplinas específicas para a prática docente. Além disso, é evidente a presença de disciplinas como a puericultura, economia doméstica, costura e bordado, que reforçavam a ideologia de formação de uma mulher voltada para o cuidado de uma casa e de seus filhos. Ademais, a concepção de que a mulher é a pessoa mais adequada para atuar no ensino primário foi historicamente tão forte que construiu um imaginário social no qual o homem tem um espaço limitado de atuação na educação de crianças. 


\section{THE CHURCH AND THE STATE: REFLECTIONS ON PRIMARY TEACHER TRAINING IN THE PERIOD 1946- 1979}

ABSTRACT: The study on the formation of the primary teacher is of fundamental importance for the understanding about the constitution of society and the different roles assumed by the Catholic Church that, historically, enjoyed the power of education to maintain social control. This study sought to analyze the relation of the Catholic Church to the formation of teachers in the Triângulo Mineiro-MG, from 1946 to 1979. For this purpose, we investigated in Stricto Sensu graduate studies that discuss the formation of the primary teacher in the Triangulo Mineiro, the state of the art of this theme. We found 20 papers that deal with it, having as subjects 43 primary teachers, of whom 21 studied in confessional schools and 22 teachers who, although they studied in secular schools, spread in their speech the precepts spread by the Catholic Church from 1946 to 1979. We used as a methodology Content Analysis according to Bardin (2016). From the analyzes, we identified that the Church was an instrument in partnership with the State for the maintenance of the social order in force between 1946 and 1979. In this way, the precepts spread by the Catholic Church were disseminated in Catholic schools and secular schools.

KEYWORDS: Church. Teacher training. Woman. State.

\section{LA IGLESIA Y EL ESTADO: REFLEXIONES SOBRE LA FORMACIÓN DEL PROFESOR PRIMARIO EN EL} PERÍODO DE 1946-1979

RESUMEN: El estudio sobre la formación del profesor primario es de fundamental importancia para el entendimiento acerca de la constitución de la sociedad y los diferentes roles asumidos por la Iglesia Católica que, históricamente, disfrutó del poder de la educación para el mantenimiento de control social. Este estudio buscó analizar la relación de la Iglesia Católica con la formación de profesores en el Triángulo Mineiro - MG, en el período de 1946 a 1979. Para ello, investigamos, en trabajos de postgrado Stricto Sensu que discuten la formación del profesor primario en el Triángulo Mineiro, el estado del arte de ese tema. Encontramos 20 trabajos que lo abordan, teniendo como sujetos 43 profesores primarios, de los cuales 21 estudiaron en escuelas confesionales y 22 profesores que, aunque habían estudiado en escuelas laicas, difundían en sus discursos los preceptos difundidos por la Iglesia Católica en el período de 1946 a 1979. Utilizamos como metodología el Análisis de Contenido según Bardin (2016). A partir de los análisis, identificamos que la Iglesia fue un instrumento en asociación con el Estado para el mantenimiento del orden social vigente en el período de 1946 a 1979. De esta forma, los preceptos difundidos por la Iglesia Católica fueron divulgados en las escuelas católicas y en las escuelas laicas.

PALABRAS CLAVE: Iglesia. Formación de profesores. Mujer. Estado.

NOTA

1) A política ultramontana "foi uma resposta da Igreja às ameaças que vinham se avolumando desde a ruptura das relações feudais e da ética católica. Desta forma foi uma reação católica à modernidade que prega a independência da Igreja uma separação entre estado e Igreja. 


\section{REFERÊNCIAS}

ALMEIDA, J. S. Mulheres na educação: missão, vocação e destino? In: SAVIANI, Dermeval et al. (Org.). O legado educacional do século XX no Brasil. Campinas, SP: Autores Associados, 2004.

ARAÚJO, J. C. S. Igreja Católica no Brasil: um estudo de mentalidade ideológica. São Paulo: Paulinas, 1986.

BARDIN, L. Análise de conteúdo. Tradução Luís Antero Reto e Augusto Pinheiro. São Paulo: Edições 70, 2016.

BRASIL. Decreto-Lei no 8.530, de 2 de janeiro de 1946. Lei Orgânica do Ensino Normal. Disponível em: <http://www2.camara.leg.br/legin/fed/declei/1940-1949/decreto-lei8530-2-janeiro-1946-458443-publicacaooriginal-1-pe.html>. Acesso em: 26 nov. 2015.

BRASIL. Lei no 5.692 de 11 de agosto de 1971. Coleção de Leis do Brasil. p.59, v. 5. Disponível em: <http://www2.camara.leg.br/legin/fed/lei/1970-1979/lei-5692-11-agosto1971-357752-publicacaooriginal-1-pl.html>. Acesso em: 26 nov. 2015.

BURKE, P. (Org.). A Escrita da história: novas perspectivas. Tradução Magda Lopes. São Paulo: Editora UNESP, 1992.

CHARTIER, R. A História cultural: entre práticas e representações. 2. ed. Portugal: DIFELDifusão Editorial S.A, 1990.

COSTA, A. P.; AMADO, J. Análise de conteúdo suportada por software. Aveiro, Portugal: Editora Ludomedia, 2018.

FERREIRA, H. O. Colégio Normal Nossa Senhora do Patrocínio: um instrumento de educação feminina na Zona do Alto Paranaíba em Minas Gerais: 1928-1950. Tese (Doutorado em História) - Faculdade de História, Direito e Serviço Social, Universidade Estadual Paulista, Franca, 2006.

FERREIRO, E.; TEBEROSKY, A. Psicogênese da língua escrita. Porto Alegre: Artes Médicas, 1991.

LOPES, E. M. T. Da Sagrada Missão Pedagógica. Bragança Paulista, SP: Editora Universitária São Francisco, 2003.

LUSTOSA, O. F. A presença da Igreja no Brasil: história e problemas; 1500-1968. São Paulo: Ed. Giro, 1977. 
LIMA, M. C.; FERREIRA, A. G

MAINWARING, S. Igreja Católica e política no Brasil (1916-1985). Tradução Heloisa Braz de Oliveira Prieto. São Paulo: Brasiliense, 1989.

MANOEL, I. A. Igreja e educação feminina (1859-1919). São Paulo: UNESP, 1996.

MARTINS, R. M. S. Ser professora na república: modos de pensar, sentir e agir (1930-1950). 2010. Dissertação (Mestrado) - Universidade Federal de Uberlândia, Uberlândia, 2010.

MELO, G. F. Por trás dos muros escolares: luzes e sombras na educação feminina (Colégio N. Sra. Das Dores - Uberaba 1940/1966). 2002. Dissertação (Mestrado em Educação) Universidade Federal de Uberlândia, Uberlândia, 2002.

MOURA, L. D. A educação católica no Brasil: passado, presente, futuro. 2. ed. São Paulo: Edições Loyola, 2000.

NEVES, G. T. A. A educação feminina no projeto siqueirano: 1939 - 1973. 2005. 209 f. Dissertação (Mestrado) - Universidade Federal de Uberlândia, Uberlândia, 2005.

ROZETTI, I. Colégio Imaculada Conceição: a história do curso Normal (Tupaciguara-MG, 1961-1977). Dissertação (Mestrado) - Universidade Federal de Uberlândia, Uberlândia, 2011.

SAVIANI, D. História das ideias pedagógicas no Brasil. Campinas, SP: Autores Associados, 2009.

SILVA, M. B. O curso Normal do Colégio Sagrado Coração de Jesus Araguari - MG (19301947). 2006. Dissertação (Mestrado) - Universidade Federal de Uberlândia, Uberlândia, 2006.

Michelle Castro LiMA: Doutora em Educação pela Universidade Federal de Uberlândia (2016). Atualmente é professora no curso de Pedagogia do Instituto Federal Goiano campus Morrinhos. Tem experiência na área de Educação, com ênfase em HISTÓRIA DA EDUCAÇÃO, atuando principalmente nos seguintes temas: alfabetização, memória, formação de professor, práticas e currículo.

ORCID: https://orcid.org/0000-0002-3352-9184

E-mail:michelle.lima@ifgoiano.edu.br 


\begin{abstract}
Antônio Gomes Ferreira: Professor associado de Ciências da Educação na Faculdade de Psicologia e Ciências da Educação da Universidade de Coimbra, Portugal, e diretor da Faculdade de Psicologia e Ciências da Educação desde 2015. É coordenador do Grupo de Políticas e Organizações Educativas e Dinâmicas Educacionais do Centro de Estudos Interdisciplinares do século $X X$ da Universidade de Coimbra.

ORCID: https://orcid.org/0000-0002-3281-6819

E-mail: michellecl82@gmail.com
\end{abstract}

Este periódico utiliza a licença Creative Commons Attribution 3.0, para periódicos de acesso aberto (Open Archives Iniciative - OAI). 